\title{
Uso de calcário na amenização da toxidez de cobre em videiras jovens
}

\section{Use of limestone in alleviating toxicity of copper in young vines}

\section{Paula Duarte de OLIVEIRA ${ }^{1}$; Vítor Gabriel AMBROSINI ${ }^{2}$; George Wellington Bastos de MELO ${ }^{3}$; Jovani ZALAMENA ${ }^{4}$; Gustavo BRUNETTO ${ }^{5}$}

1 Eng. Agrônoma; Mestranda no Programa de Pós-Graduação em Fitotecnia; Universidade Federal do Rio Grande do
Sul (UFRGS); poulduarte@hotmail.com
2 Eng. Agrônomo; Mestrando no Programa de Pós-Graduação em Agroecossistemas; Universidade Federal de Santa
Catarina (UFSC); vgambrosini@gmail.com
Eng. Agrônomo; Doutor em Ciência do Solo; Pesquisador na Empresa Brasileira de Pesquisa Agropecuária
(EMBRAPA Uva e Vinho); wellington.melo@embrapa.br
4 Eng. Agrônomo; Doutor em Manejo do Solo; Pós-Doutorando no Programa de Pós-Graduação em Ciência do Solo;
Universidade Federal de Santa Maria (UFSM); jovanizalamena@yahoo.com.br
Autor para correspondência; Eng. Agrônomo; Doutor em Ciência do Solo; Professor Adjunto no Departamento de
Solos; Centro de Ciências Rurais; UFSM. Av. Roraima, 1000, Camobi, CEP: $97105-340$, Santa Maria - RS, Brasil.
Telefone: (55) 3220-8108. brunetto.gustavo@gmail.com

Recebido em: 25-09-2014; Aceito em: 24-06-2015

\section{Resumo}

A aplicação de calcário pode diminuir a toxidez de $\mathrm{Cu}$ em videiras jovens. O trabalho objetivou avaliar o efeito da calagem em solos com adição de Cu como estratégia de amenizar a toxidez do metal pesado em videiras jovens. $O$ experimento foi conduzido em casa de vegetação utilizando solo coletado em uma área sem histórico de cultivo. $O$ solo foi dividido em três porções iguais, que receberam doses de calcário correspondentes a 0,12,6 e 25,2 $\mathrm{Mg} \mathrm{ha}^{-1}$. Após 45 dias de incubação, o solo recebeu doses crescentes de $\mathrm{Cu}: 0,50,100,200$ e $300 \mathrm{mg} \mathrm{kg}^{-1}$ de solo, aplicadas na forma de sulfato de Cu. Posteriormente, o solo foi incubado novamente por 45 dias. Em vasos contendo três quilogramas de solo, foram transplantadas estacas de videira 'Niágara Rosada'. Após 103 dias de cultivo, os ramos das videiras foram podados e descartados. Aos 46 dias após a primeira poda, foram determinadas as clorofilas a e $b$ (Índice de Clorofila Falker - ICF). O cultivo foi finalizado aos 77 dias após a primeira poda, quando foi determinada a área foliar e foi coletado material vegetal para a determinação da matéria seca (MS) de raízes e da parte aérea, e o acúmulo de $\mathrm{N}$, $\mathrm{P}, \mathrm{K}, \mathrm{Ca}, \mathrm{Mg}$ e Cu em cada parte. $\mathrm{O}$ aumento das doses de Cu reduziu a MS de raízes e da parte aérea, a área foliar, as clorofilas $a$ e $b$ (ICF) e a absorção de todos os nutrientes nas videiras jovens. A calagem minimizou os efeitos causados pelo excesso de $\mathrm{Cu}$.

Palavras-chave adicionais: absorção de nutrientes; calagem; metal pesado; Vitis sp.

\begin{abstract}
Liming can reduce the toxicity of $\mathrm{Cu}$ in young vines. The study aimed to evaluate the effect of liming on soils with addition of $\mathrm{Cu}$, as strategy to mitigate the toxicity of heavy metal in young vines. The experiment was conducted in a greenhouse using soil collected in area without history of cultivation. The soil was divided into three equal portions, which received doses of lime corresponding to $0,12.6$ and $25.2 \mathrm{Mg} \mathrm{ha}^{-1}$. After 45 days of incubation, the soil has received increasing doses of Cu: $0,50,100,200$ and $300 \mathrm{mg} \mathrm{kg}^{-1}$, as a Cu sulfate. Subsequently, the soil was incubated again for 45 days. In pots containing three kilograms of soil, vine cuttings of 'Niagara Rosada' were transplanted. After 103 days of cultivation, the branches of the vines were pruned and discarded. 46 days after the first pruning, were determined chlorophyll $a$ and $b$ (Falker Chlorophyll Index $-\mathrm{FCl}$ ). The cultivation was finished at 77 days after the first pruning, when it was determined the leaf area and plant material was collected for determination of dry matter (DM) of roots and shoots, and the accumulation of $\mathrm{N}, \mathrm{P}, \mathrm{K}, \mathrm{Ca}, \mathrm{Mg}$ and $\mathrm{Cu}$ in each part. Increasing doses of $\mathrm{Cu}$ reduced the dry matter of roots and shoots, leaf area, chlorophylls $a$ and $b(\mathrm{FCl})$ and uptake of all nutrients in young vines. Liming minimized the effects caused by Cu excess.
\end{abstract}

Additional keywords: nutrients uptake; liming; heavy metal; Vitis sp.

\section{Introdução}

As frequentes aplicações de fungicidas $e$ caldas à base de $\mathrm{Cu}$ para o controle de doenças fúngicas em videiras (Vitis sp.) em produção podem causar o acúmulo desse metal pesado no solo ao longo dos anos, principalmente na fração orgânica (Nogueirol et al., 2010; Ruyters et al., 2013; Brunetto et al., 2014a, 2014b). Com o decréscimo da produtividade de uva, os vinhedos mais antigos em produção são erradicados e, em seguida, o solo é revolvido para um novo transplante de videiras 
jovens. Como consequência, a oxidação da matéria orgânica é potencializada, aumentando a disponibilidade de $\mathrm{Cu}$ que, apesar de ser um micronutriente essencial às plantas, pode ser incrementado no solo a teores que podem ser tóxicos (Chen et al., 2013; Juang et al., 2014).

As plantas expostas ao alto teor de $\mathrm{Cu}$ podem apresentar redução da concentração de clorofilas e da taxa fotossintética, causadas indiretamente por alguns fatores como: destruição da estrutura interna dos cloroplastos e as modificações na composição das membranas dos tilacoides (Borghi et al., 2007), inibição de enzimas responsáveis pela biossíntese da clorofila (Zengin \& Munzuroglu, 2005) e danos no aparato fotossintético pelo efeito do $\mathrm{Cu}$ na cadeia de transporte de elétrons (Cambrollé et al., 2013).

$\mathrm{O}$ excesso de $\mathrm{Cu}$ no solo também pode causar restrição ao crescimento radicular, danos na cutícula e rachaduras nas raízes, inibindo a absorção de água e de nutrientes pelas raízes (Sheldon \& Menzies, 2005; Michaud et al., 2008; Kopittke et al., 2009; Chen et al., 2013). Como consequência, o alto teor de $\mathrm{Cu}$ no solo pode prejudicar o incremento da matéria seca das videiras jovens, retardando seu crescimento.

Os efeitos tóxicos do excesso de $\mathrm{Cu}$ em videiras jovens transplantadas em solos com altos teores do metal pesado, no entanto, podem ser minimizados com a adição de calcário, que promove o aumento do valor de $\mathrm{pH}$ e da capacidade de troca de cátions efetiva (CTC efetiva) do solo (Joris et al., 2012). A elevação do $\mathrm{pH}$ pela aplicação de calcário aumenta a disponibilidade dos macronutrientes no solo (Sousa et al., 2007) e reduz a disponibilidade do $\mathrm{Cu}$ às plantas, uma vez que parte do elemento pode ser adsorvido aos grupos funcionais de superfície de partículas reativas e outra parte pode ser precipitada na solução (Agbenin \& Olojo, 2004; Joris et al., 2012). Ainda, o $\mathrm{Ca}$ e o $\mathrm{Mg}$ derivados do calcário podem competir com o $\mathrm{Cu}$ pelos sítios de adsorção da superfície das raízes, reduzindo a absorção do metal pesado pela planta (Luo et al., 2008; Kopittke et al., 2011). Portanto, a prática da calagem pode ser uma importante estratégia para reduzir os efeitos tóxicos do $\mathrm{Cu}$ para as videiras jovens. No entanto, não é suficientemente conhecida qual a melhor dose de calcário a ser aplicada e, consequentemente, o valor de $\mathrm{pH}$ do solo que pode minimizar a toxidez do $\mathrm{Cu}$ em videiras jovens cultivadas em solo de textura arenosa.

O trabalho objetivou avaliar o efeito da calagem em solos com a adição de Cu como estratégia de amenizar a toxidez do metal pesado em videiras jovens.

\section{Material e métodos}

O experimento foi conduzido em casa de vegetação, no período de agosto de 2012 a fevereiro de 2013, utilizando um Argissolo Vermelho (Embrapa, 2013) coletado em área de campo natural sem histórico de cultivo, no município de Farroupilha - RS. Após a coleta, o solo foi seco ao ar, passado em peneira com malha de $2 \mathrm{~mm}$ e submetido à análise química para a determinação das características iniciais, que eram: argila $530 \mathrm{~g} \mathrm{~kg}^{-1}$; matéria orgânica do solo $28 \mathrm{~g} \mathrm{~kg}^{-1}$; pH em água (1:1) 4,3; Índice SMP 4,4; $\mathrm{Al}, \mathrm{Ca}$ e $\mathrm{Mg}$ trocáveis, 6,79; 0,28 e $0,31 \quad \mathrm{cmol}_{\mathrm{c}} \mathrm{dm}^{-3}$, respectivamente (ambos extraídos por $\mathrm{KCl} 1 \mathrm{~mol} \mathrm{~L}^{-1}$ ); $\mathrm{P}$ disponível 3,1 $\mathrm{mg} \mathrm{dm}^{-3}, \mathrm{~K}$ trocável $31,0 \mathrm{mg} \mathrm{dm}^{-3} \mathrm{e}$ $\mathrm{Cu}$ disponível $0,8 \mathrm{mg} \mathrm{dm}^{-3}$ (ambos extraídos por Mehlich 1) (Tedesco et al., 1995).

O solo foi submetido à aplicação de $200 \mathrm{~kg} \mathrm{ha}^{-1}$ de $\mathrm{P}_{2} \mathrm{O}_{5}$ e de $90 \mathrm{~kg} \mathrm{ha}^{-1}$ de $\mathrm{K}_{2} \mathrm{O}$ para elevar os teores até o nível de suficiência (CQFS-RS/SC, 2004) e, em seguida, foi dividido em três porções iguais. A fonte de $\mathrm{K}$ foi o cloreto de potássio $(\mathrm{KCl})$, e de $\mathrm{P}$ o superfosfato triplo (SFT). A primeira porção foi mantida sem calagem; na segunda porção, foi aplicado 0 correspondente a $12,6 \mathrm{Mg} \mathrm{ha}^{-\uparrow}$ de calcário dolomítico (PRNT 85,7\%), correspondente a 1 SMP; na terceira porção do solo, foi adicionado o correspondente a 25,2 $\mathrm{Mg} \mathrm{ha}^{-1}$ de calcário dolomítico, equivalente a 2 SMP. O calcário foi adicionado sobre o solo e homogeneizado manualmente, até mistura total do solo com o calcário. A quantidade necessária de calcário para cada SMP foi estipulada de acordo com a equação proposta por Rodighero et al. (2012). Posteriormente, o solo sem a aplicação de calcário e com a aplicação equivalente a 1 e 2 SMP foi acondicionado em sacos de plástico, nos quais foi adicionada água para manter $80 \%$ da capacidade de campo. O solo permaneceu incubado durante 45 dias. Diariamente, cada porção do solo foi pesada e, quando necessário, foi adicionada água para manter a capacidade de campo a $80 \%$.

Após a incubação, o solo foi submetido à adição de doses crescentes de Cu: 0, 50, 100, 200 e $300 \mathrm{mg} \mathrm{kg}^{-1}$ de solo seco. Estas doses de Cu foram adicionadas porque, em estudos preliminares, observou-se que videiras cultivadas em solos com doses de $\mathrm{Cu}$ próximas a $100 \mathrm{mg} \mathrm{kg}^{-1}$, normalmente, apresentaram menor produção de matéria seca da parte aérea e das raízes. Por isso, foram criadas doses abaixo e acima do valor. A fonte de $\mathrm{Cu}$ foi o sulfato de $\mathrm{Cu}$, aplicado sobre o solo, homogeneizado, submetido à adição de água para elevar a capacidade de campo até $80 \%$ e incubado por mais 45 dias. O delineamento experimental utilizado foi em blocos ao acaso, com três repetições, em arranjo fatorial $3 \times 5$ (doses de calcário $x$ doses de $\mathrm{Cu}$ ).

Após as duas incubações, foi coletado solo para determinar os valores de $\mathrm{pH}$ do solo obtidos com as doses de calcário aplicadas. $\mathrm{O}$ valor de $\mathrm{pH}$ em água (relação 1:1) do solo foi de 4,0 no solo sem a adição de calcário; 5,5 no solo com a adição de 12,6 $\mathrm{Mg} \mathrm{ha}^{-1}$ de calcário; e 6,7 no solo com adição de 25,2 $\mathrm{Mg} \mathrm{ha}^{-1}$ de calcário.

Três quilogramas de solo foram adicionados em vasos, que foram distribuídos sobre bancadas em casa de vegetação com controle de temperatura e umidade. Em 17 de agosto de 2012, foi transplantada 
em cada vaso uma estaca de videira 'Niágara Rosada' com três gemas. No decorrer do experimento, realizou-se a poda, permanecendo apenas um broto por estaca, sendo o ramo tutorado verticalmente ao longo da condução do experimento. Os vasos foram trocados de posição nas bancadas, semanalmente, para minimizar a desuniformidade de iluminação. Ao longo do cultivo, foram aplicados $50 \mathrm{mg} \mathrm{kg}^{-1}$ de $\mathrm{N}$ em cada unidade experimental, divididos em duas vezes ( 2 de outubro e 28 de novembro de 2012). A fonte de $\mathrm{N}$ foi a ureia (44\% de $\mathrm{N})$, aplicada dissolvida em água. Diariamente, os vasos foram pesados e, quando necessário, foi adicionada água para manter a capacidade de campo a $80 \%$.

Após 103 dias de cultivo, os ramos das videiras foram podados e descartados. Aos 46 dias após a primeira poda, foi mensurada a altura de cada planta, em cm, desde a inserção do ramo na estaca até à última folha desenvolvida, utilizando uma régua graduada. $O$ teor de clorofila $a$ e $b$, expresso como Índice de Clorofila Falker (ICF), foi determinado com o clorofilômetro CFL1030 da marca Falker, procedendo-se a uma leitura por planta no centro da terceira folha completa, contada de baixo para cima. Com os resultados dos teores de clorofila $a$ e $b$ (ICF), foram obtidas as relações de clorofila $a / b$.

Aos 77 dias após a primeira poda, a parte aérea das plantas foi cortada rente à superfície do solo com uma tesoura de poda. Em seguida, as folhas foram separadas dos ramos, e realizou-se a determinação da área foliar de cada planta com o medidor eletrônico LI3100 Area Metter, marca LI-COR.

O solo de cada vaso foi retirado, e as raízes foram separadas e lavadas em água corrente, passadas em solução de $\mathrm{HCl} 0,5 \mathrm{~mol} \mathrm{~L}^{-1}$ (permanecendo em contato com essa solução por, aproximadamente, 3 minutos), depois foram novamente lavadas em água corrente e, posteriormente, submetidas à lavagem com água destilada. Os ramos, as folhas e as raízes foram secos em estufa com circulação de ar forçado a $65^{\circ} \mathrm{C}$ até atingirem massa constante. $\mathrm{O}$ material vegetal seco foi moído e armazenado, e os teores totais de $\mathrm{N}, \mathrm{P}, \mathrm{K}, \mathrm{Ca}, \mathrm{Mg}$ e $\mathrm{Cu}$ foram determinados utilizando metodologia descrita pela Embrapa (1997). Para determinar o acúmulo de nutrientes nas raízes e na parte aérea da planta, multiplicou-se o teor do nutriente pela massa seca do órgão vegetal. O somatório do acúmulo do nutriente nas raízes e na parte aérea equivale ao acúmulo na planta inteira.

Os resultados obtidos foram submetidos ao teste de homocedasticidade e, posteriormente, à análise de variância. Quando a mesma foi significativa, aplicou-se o teste de Tukey $(p<0,05)$ para comparar as médias dos tratamentos com calagem dentro da mesma dose de $\mathrm{Cu}$; e para os resultados entre as doses de $\mathrm{Cu}$, dentro da mesma dose de calcário, foram aplicadas regressões polinomiais. As análises estatísticas foram realizadas utilizando o software Sisvar 5.3 (Build 75) (Ferreira, 2011).

\section{Resultados e discussão}

A análise de variância revelou efeito de interação dos fatores $\mathrm{Cu}$ e calagem para todas as variáveis, exceto para clorofila a (ICF). Os resultados desta variável e o desdobramento da análise de variância das demais variáveis estão apresentados nas Tabelas $1-5$.

A produção de matéria seca (MS) de raízes e a altura das plantas diminuíram de forma linear com o incremento do teor de Cu disponível no solo, nos tratamentos sem adição de calcário (Tabela 1). A redução relativa dessas variáveis foi de $80 \%$ na MS de raízes e de $72 \%$ na altura das plantas, quando comparados os resultados obtidos nos tratamentos com a maior e a menor dose adicionada no solo. A MS da parte aérea e a área foliar das videiras jovens no solo, sem a adição de calcário, de acordo com as análises de regressão, aumentaram aproximadamente até às doses de 100 e $109 \mathrm{mg} \mathrm{kg}^{-1}$ de Cu adicionado, nesta ordem; diminuindo, a partir daí, em 75 e 55\%, respectivamente, até à maior dose aplicada (Tabela 1). Além disso, observa-se que a redução da produção de MS de raízes $(80 \%)$ foi mais acentuada em relação à MS da parte aérea $(75 \%)$.

Esses resultados corroboram com os de outros trabalhos realizados com diferentes cultivares de videiras jovens cultivadas com teores altos de $\mathrm{Cu}$ (Melo et al., 2008; Toselli et al., 2009; Chen et al., 2013; Juang et al.; 2014). A redução da produção de MS da parte aérea e das raízes, assim como da área foliar, é causada pela exposição do sistema radicular das plantas ao alto teor de $\mathrm{Cu}$ no solo, que pode danificar a cutícula e causar rachaduras nas raízes, provocando a má-formação, inibição do crescimento e da produção de biomassa das raízes (Sheldon \& Menzies, 2005; Michaud et al., 2008; Juang et al.; 2014). Em função disso, a absorção de água e de nutrientes pelas raízes é prejudicada, causando também a redução da biomassa da parte aérea das plantas (Kopittke et al., 2009).

Com a adição de $12,6 \mathrm{Mg} \mathrm{ha}^{-1}$ de calcário, que elevou o valor de $\mathrm{pH}$ até 5,5 , os efeitos do $\mathrm{Cu}$ não foram significativos sobre a MS de raízes e da área foliar, enquanto a MS da parte aérea e a altura das plantas aumentaram de forma quadrática, sendo o valor máximo obtido com doses de $\mathrm{Cu}$ aproximadas a 142 e $170 \mathrm{mg} \mathrm{kg}^{-1}$, respectivamente (Tabela 1). A partir dessas doses de Cu, essas variáveis diminuíram. Apesar disso, com a maior dose de $\mathrm{Cu}$ aplicada no solo, a redução dessas variáveis foi menor que a daquelas observadas nos tratamentos sem a adição de calcário: com adição de $12,6 \mathrm{Mg} \mathrm{ha}^{-1}$ de calcário, a MS da parte aérea aumentou de 0,8 para $1,5 \mathrm{~g}$, e a altura das plantas incrementou de 5,5 para $14,2 \mathrm{~cm}$ em relação ao mesmo tratamento sem a adição de calagem (Tabela 1). 
Tabela 1 - Matéria seca das raízes e da parte aérea, altura da planta e área foliar de videiras jovens cultivadas em solo com doses crescentes de Cu e de calcário. Dry matter of roots and shoots, plant height and leaf area of young vines grown in soil with increasing doses of $\mathrm{Cu}$ and limestone.

\begin{tabular}{|c|c|c|c|c|c|c|c|}
\hline \multirow{2}{*}{$\begin{array}{l}\text { Calcário } \\
\left(\mathrm{Mg} \mathrm{ha}^{-1}\right)\end{array}$} & \multicolumn{5}{|c|}{$\begin{array}{c}\mathrm{Cu} \\
\left(\mathrm{mg} \mathrm{kg}^{-1}\right)\end{array}$} & \multirow[t]{2}{*}{ Regressão } & \multirow{2}{*}{$\mathrm{R}^{2}$} \\
\hline & 0 & 50 & 100 & 200 & 300 & & \\
\hline & \multicolumn{7}{|c|}{ (1)Matéria seca das raízes (g) } \\
\hline 0,0 & $3,9 \mathrm{a}$ & $6,0 \mathrm{a}$ & $4,4 a$ & $1,5 b$ & $1,0 \mathrm{C}$ & $\hat{y}=5,27-0,014 x$ & $0,71^{x \times}$ \\
\hline 12,6 & $3,1 \mathrm{~b}$ & $2,1 \mathrm{~b}$ & $3,4 \mathrm{a}$ & $3,9 a$ & $3,3 \mathrm{a}$ & - & ns \\
\hline 25,2 & $3,8 a b$ & $1,7 \mathrm{~b}$ & $1,6 \mathrm{c}$ & $0,8 \mathrm{~b}$ & $1,9 \mathrm{~b}$ & $\hat{y}=3,60-0,031 x+0,00008 x^{2}$ & $0,90^{* \pi}$ \\
\hline CV (\%) & & & 14,41 & & & & \\
\hline & & & & ${ }^{(1)}$ Matéria & eca da pal & aérea $(\mathrm{g})$ & \\
\hline 0,0 & $1,4 \mathrm{a}$ & $2,7 \mathrm{a}$ & $2,2 \mathrm{a}$ & $1,4 b$ & $0,8 \mathrm{~b}$ & $\hat{y}=1,74+0,008 x-0,00004 x^{2}$ & $0,68^{* \pi}$ \\
\hline 12,6 & $1,7 \mathrm{a}$ & $2,0 \mathrm{~b}$ & $2,8 \mathrm{a}$ & $2,9 \mathrm{a}$ & $1,5 \mathrm{a}$ & $\hat{y}=1,55+0,017 x-0,00006 x^{2}$ & $0,90^{\star *}$ \\
\hline 25,2 & $1,8 \mathrm{a}$ & $0,6 \mathrm{c}$ & $1,1 \mathrm{~b}$ & $0,3 c$ & $2,1 \mathrm{a}$ & $\hat{y}=1,73-0,018 x+0,00006 x^{2}$ & $0,74^{\star \pi}$ \\
\hline CV (\%) & & & 20,25 & & & & \\
\hline & & & & ${ }^{(1)} \mathrm{Alt}$ & a da plan & $(\mathrm{cm})$ & \\
\hline 0,0 & $23,9 \mathrm{a}$ & $21,4 \mathrm{a}$ & $18,7 \mathrm{a}$ & $14,3 \mathrm{~b}$ & $5,5 b$ & $\hat{y}=24,47-0,059 x$ & $0,98^{* x}$ \\
\hline 12,6 & $16,9 \mathrm{~b}$ & $13,0 \mathrm{~b}$ & $19,5 \mathrm{a}$ & $29,5 \mathrm{a}$ & $14,2 \mathrm{a}$ & $\hat{y}=12,62+0,136 x-0,0004 x^{2}$ & $0,44^{* \pi}$ \\
\hline 25,2 & $15,2 b$ & $7,5 \mathrm{c}$ & $12,7 \mathrm{~b}$ & $3,0 \mathrm{c}$ & $17,5 \mathrm{a}$ & $\hat{y}=15,46-0,129 x+0,0004 x^{2}$ & $0,57^{* *}$ \\
\hline \multirow{2}{*}{\multicolumn{8}{|c|}{ CV (\%) }} \\
\hline & & & & & & & \\
\hline 0,0 & 250,7 b & 352,8 a & $308,1 \mathrm{a}$ & $269,1 \mathrm{~b}$ & $124,4 \mathrm{c}$ & $\hat{y}=270,26+1,09 x-0,005 x^{2}$ & $0,92^{* x}$ \\
\hline 12,6 & $284,2 \mathrm{ab}$ & 267,4 a & $257,0 a b$ & 399,2 a & $233,1 \mathrm{~b}$ & - & ns \\
\hline 25,2 & $346,2 \mathrm{a}$ & $104,5 \mathrm{~b}$ & $168,5 \mathrm{~b}$ & $80,3 \mathrm{c}$ & $396,1 \mathrm{a}$ & $\hat{y}=326,56-3,63 x+0,012 x^{2}$ & $0,85^{* x}$ \\
\hline \multicolumn{8}{|l|}{ CV (\%) } \\
\hline
\end{tabular}

No solo com a adição de $25,2 \mathrm{Mg} \mathrm{ha}^{-1}$ de calcário, que elevou o valor de $\mathrm{pH}$ ao final da incubação até 6,7 , a MS de raízes e da parte aérea, a altura e a área foliar das videiras jovens diminuíram com o incremento da dose de $\mathrm{Cu}$, mas de forma quadrática (Tabela 1). Apesar disso, a redução teve menos impacto nessas variáveis em relação ao solo sem a adição de calcário. Isso pode ser constatado pelo teste de separação de médias na dose de 300 $\mathrm{mg} \mathrm{kg}^{-1}$ de $\mathrm{Cu}$, que mostrou incremento dessas variáveis com a adição do calcário (Tabela 1).

A amenização dos efeitos tóxicos do $\mathrm{Cu}$ pela calagem sobre as variáveis de crescimento das videiras jovens pode ser consequente do aumento da capacidade de troca de cátions, que pode aumentar a adsorção de $\mathrm{Cu}$, diminuindo sua disponibilidade às plantas (Joris et al., 2012). Além disso, com a adição de calcário, ocorre o incremento de íons $\mathrm{OH}^{-}$livres na solução, que podem complexar o $\mathrm{Cu}^{2+}$, formando precipitado (Agbenin \& Olojo, 2004), o que diminui a quantidade absorvida pelas plantas e, por consequência, seu potencial de toxidez. A adição de $\mathrm{Ca}$ e $\mathrm{Mg}$ no solo pela calagem também pode ter contribuído para o crescimento das plantas, porque esses elementos competem com os íons de $\mathrm{Cu}^{2+}$ livres no solo pela adsorção na superfície das raízes, reduzindo a absorção do metal pesado, posteriormente (Luo et al., 2008; Kopittke et al., 2011), e também sua translocação das raízes para a parte aérea (Juang et al.; 2012; Chen et al., 2013). A clorofila a (ICF) nas folhas diminuiu com a adição de $25,2 \mathrm{Mg} \mathrm{ha}^{-1}$ de calcário, em relação ao tratamento sem calagem, independentemente da dose de $\mathrm{Cu}$ aplicada (Tabela 2). Provavelmente, a redução na clorofila a (ICF) com o aumento da calagem está relacionada com a concomitante diminuição na produção de raízes nas menores doses de Cu (Tabela 1), o que inibe a absorção de água e de nutrientes - como o $\mathrm{N}$, que teve sua absorção reduzida com a adição das menores doses de $\mathrm{Cu}$ (Tabelas 3, 4 e 5) (Li et al., 2013). O aumento das doses de Cu também reduziu a clorofila a (ICF), independentemente da dose de calcário (Tabela 2), o que pode ter acontecido, em parte, porque houve redução na absorção de $\mathrm{N}$ e $\mathrm{Mg}$ pelas videiras submetidas às doses 0 e $25,2 \mathrm{Mg} \mathrm{ha}^{-1}$ de calcário (Tabelas 3, 4 e 5). O N é um nutriente essencial para a síntese da molécula de clorofila ( $\mathrm{Li}$ et al., 2013); e o Mg, quando em situação de excesso de $\mathrm{Cu}$, pode ser substituído pelo metal pesado na molécula de clorofila, inibindo a fotossíntese (Yruela, 2009). Além disso, o excesso de metais pesados no interior das plantas pode causar a inibição da atividade de enzimas, como, por exemplo, aquelas que atuam na biossíntese da clorofila, diminuindo sua concentração na planta (Zengin \& Munzuroglu, 2005). 
Tabela 2 - Clorofilas $a$ e $b$ (ICF) e relação clorofila $a / b$ nas folhas de videiras jovens cultivadas em solo com doses crescentes de $\mathrm{Cu}$ e de calcário. Chlorophyll $a$ and $b(F C l)$ and relation chlorophyll ab in leaves of young vines grown in soil with increasing doses of $\mathrm{Cu}$ and limestone.

\begin{tabular}{|c|c|c|c|c|c|c|c|c|}
\hline \multirow{2}{*}{$\begin{array}{l}\text { Calcário } \\
\left(\mathrm{Mg} \mathrm{ha}^{-1}\right)\end{array}$} & \multicolumn{6}{|c|}{$\begin{array}{c}\mathrm{Cu} \\
\left(\mathrm{mg} \mathrm{kg}^{-1}\right)\end{array}$} & \multirow[t]{2}{*}{ Regressão } & \multirow[t]{2}{*}{$\mathrm{R}^{2}$} \\
\hline & 0 & 50 & 100 & 200 & 300 & (2) Média & & \\
\hline & \multicolumn{8}{|c|}{ Clorofila a (ICF) } \\
\hline 0,0 & $36,3^{\mathrm{ns}}$ & $35,7^{\text {ns }}$ & $37,9^{\text {ns }}$ & $36,0^{\text {ns }}$ & $28,7^{\text {ns }}$ & $34,9 \mathrm{a}$ & - & ns \\
\hline 12,6 & 30,9 & 36,2 & 34,7 & 33,6 & 34,0 & $33,9 a b$ & - & $\mathrm{ns}$ \\
\hline 25,2 & 32,1 & 35,3 & 29,4 & 27,8 & 27,9 & $30,5 \mathrm{~b}$ & - & ns \\
\hline (1)Média & 33,1 & 35,7 & 34,0 & 32,5 & 30,2 & & $\hat{y}=34,83-0,013 x$ & $0,62^{*}$ \\
\hline CV (\%) & \multirow{2}{*}{\multicolumn{8}{|c|}{ (2) Clorofila $h$ (ICFF) }} \\
\hline & & & & & & CF) & & \\
\hline 0,0 & $14,5 \mathrm{a}$ & $11,9 a$ & $12,9 \mathrm{a}$ & $12,6 \mathrm{a}$ & $6,7 \mathrm{~b}$ & - & $\hat{y}=14,44-0,02 x$ & $0,71^{\prime \prime}$ \\
\hline 12,6 & $7,5 \mathrm{~b}$ & $11,7 a$ & $10,8 \mathrm{ab}$ & $8,5 \mathrm{~b}$ & $10,2 \mathrm{a}$ & - & - & ns \\
\hline 25,2 & $12,3 \mathrm{a}$ & $11,4 \mathrm{a}$ & $8,4 \mathrm{~b}$ & $6,5 \mathrm{~b}$ & $7,0 \mathrm{~b}$ & - & $\hat{y}=11,64-0,019 x$ & $0,79^{* \prime}$ \\
\hline \multirow{2}{*}{\multicolumn{9}{|c|}{${ }^{(2)}$ Relação clorofila $a / b$}} \\
\hline & & & & & & & & \\
\hline 0,0 & $2,5 \mathrm{~b}$ & $3,1 \mathrm{a}$ & $2,9 a$ & $2,9 \mathrm{~b}$ & $4,3 \mathrm{a}$ & - & $\hat{y}=2,54+0,0045 x$ & $0,66^{* \prime}$ \\
\hline 12,6 & $4,3 \mathrm{a}$ & $3,1 \mathrm{a}$ & $3,2 \mathrm{a}$ & $4,0 \mathrm{a}$ & $3,3 \mathrm{~b}$ & - & - & ns \\
\hline 25,2 & $2,6 \mathrm{~b}$ & $3,1 \mathrm{a}$ & $3,5 \mathrm{a}$ & $4,3 \mathrm{a}$ & $4,0 a b$ & - & $\hat{y}=2,88+0,0048 x$ & 0,76 \\
\hline CV (\%) & \multicolumn{8}{|c|}{13,95} \\
\hline
\end{tabular}

ns - não significativo; * - significativo a $p<0,05 ;{ }^{* *}$ - significativo a $p<0,01 ;{ }^{(1)}$ Médias de cada fator apresentadas apenas para a variável Clorofila a (ICF), que não apresentou efeito de interação. ${ }^{(2)}$ Valores médios seguidos pela mesma letra na coluna não diferem entre si pelo teste de Tukey $(p<0,05)$.

Tabela 3 - Valores de N, P, K, Ca, Mg e Cu acumulados nas raízes de videiras jovens cultivadas em solo com doses crescentes de $\mathrm{Cu}$ e de calcário. Values of $\mathrm{N}, \mathrm{P}, \mathrm{K}, \mathrm{Ca}, \mathrm{Mg}$ and $\mathrm{Cu}$ accumulated in roots of young vines grown in soil with increasing doses of $\mathrm{Cu}$ and limestone.

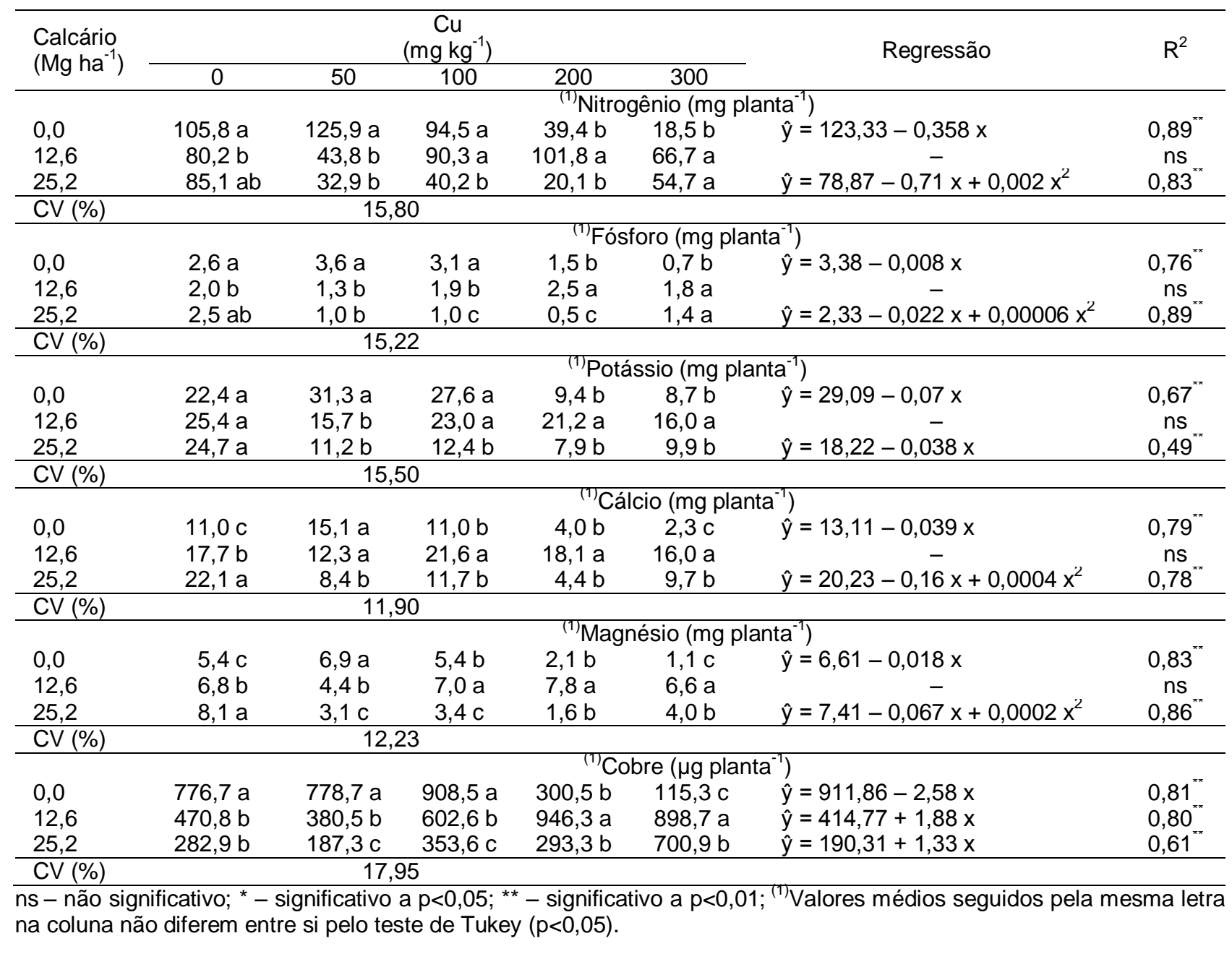


A clorofila $b$ (ICF) nas folhas também diminuiu com o incremento de $\mathrm{Cu}$ nos solos sem adição de calcário e naqueles com $25,2 \mathrm{Mg} \mathrm{ha}^{-1}$ de calcário (Tabela 2). $\mathrm{O}$ excesso de Cu na parte aérea, além de inibir a síntese de enzimas que atuam na síntese da clorofila, normalmente induz o decréscimo no conteúdo de clorofila da planta, e está associado à destruição da estrutura interna dos cloroplastos e as modificações na composição das membranas dos tilacoides (Borghi et al., 2007). Somado a isso, o $\mathrm{Cu}$ tem efeito direto na cadeia de transporte de elétrons, e seu excesso no tecido pode causar danos no aparato fotossintético, inibindo a fotossíntese (Cambrollé et al., 2013).

Em experimento com plantas de orégano (Origanum vulgare subsp. hirtum), Panou-Filotheou et al. (2001) observaram que as plantas expostas ao alto teor de Cu no solo apresentaram redução no número e no tamanho de cloroplastos, o que diminui a concentração de pigmentos fotossintéticos nas folhas. A redução da concentração de clorofila nas folhas pelo excesso de $\mathrm{Cu}$ foi constatada, também, por Cambrollé et al. (2013) em trabalho realizado com videira. Os autores atribuíram esse efeito ao decréscimo no teor de $\mathrm{N}$ e $\mathrm{Mg}$ nas folhas das plantas submetidas a altas doses do metal pesado, uma vez que esses elementos são envolvidos na síntese de clorofila. No presente experimento, foi constatado que o aumento das doses de Cu reduziu a absorção desses dois macronutrientes (Tabelas 3 e 4), podendo ser uma das causas para a diminuição das clorofilas $a$ e $b$ nas folhas.

A relação clorofila $a / b$ aumentou com o incremento das doses de $\mathrm{Cu}$ quando não houve calagem e com adição de $25,2 \mathrm{Mg} \mathrm{ha}^{-1}$ de calcário; e no solo com a aplicação de $12,6 \mathrm{Mg} \mathrm{ha}^{-1}$ de calcário, os efeitos do Cu não foram significativos (Tabela 2). Esse aumento na relação clorofila $a / b$ indica um estresse sofrido pelas plantas em função do excesso de $\mathrm{Cu}$ adicionado e pode ser consequência da redução na eficiência fotoquímica do fotossistema II, como reflexo do aumento do teor de $\mathrm{Cu}$ nos tecidos (Zengin \& Munzuroglu, 2005).

O acúmulo de Cu nas raízes, na parte aérea e na planta inteira diminuiu conforme o teor do elemento no solo foi incrementado sem a adição de calcário (Tabelas 3, 4 e 5). Essa diminuição é uma consequência da redução da MS das plantas causada pelo aumento das doses de $\mathrm{Cu}$ (Tabela 1).

Tabela 4 - Valores de N, P, K, Ca, Mg e Cu acumulados na parte aérea de videiras jovens cultivadas em solo com doses crescentes de Cu e de calcário. Values of $\mathrm{N}, \mathrm{P}, \mathrm{K}, \mathrm{Ca}, \mathrm{Mg}$ and $\mathrm{Cu}$ accumulated in shoots of young vines grown in soil with increasing doses of $\mathrm{Cu}$ and limestone.

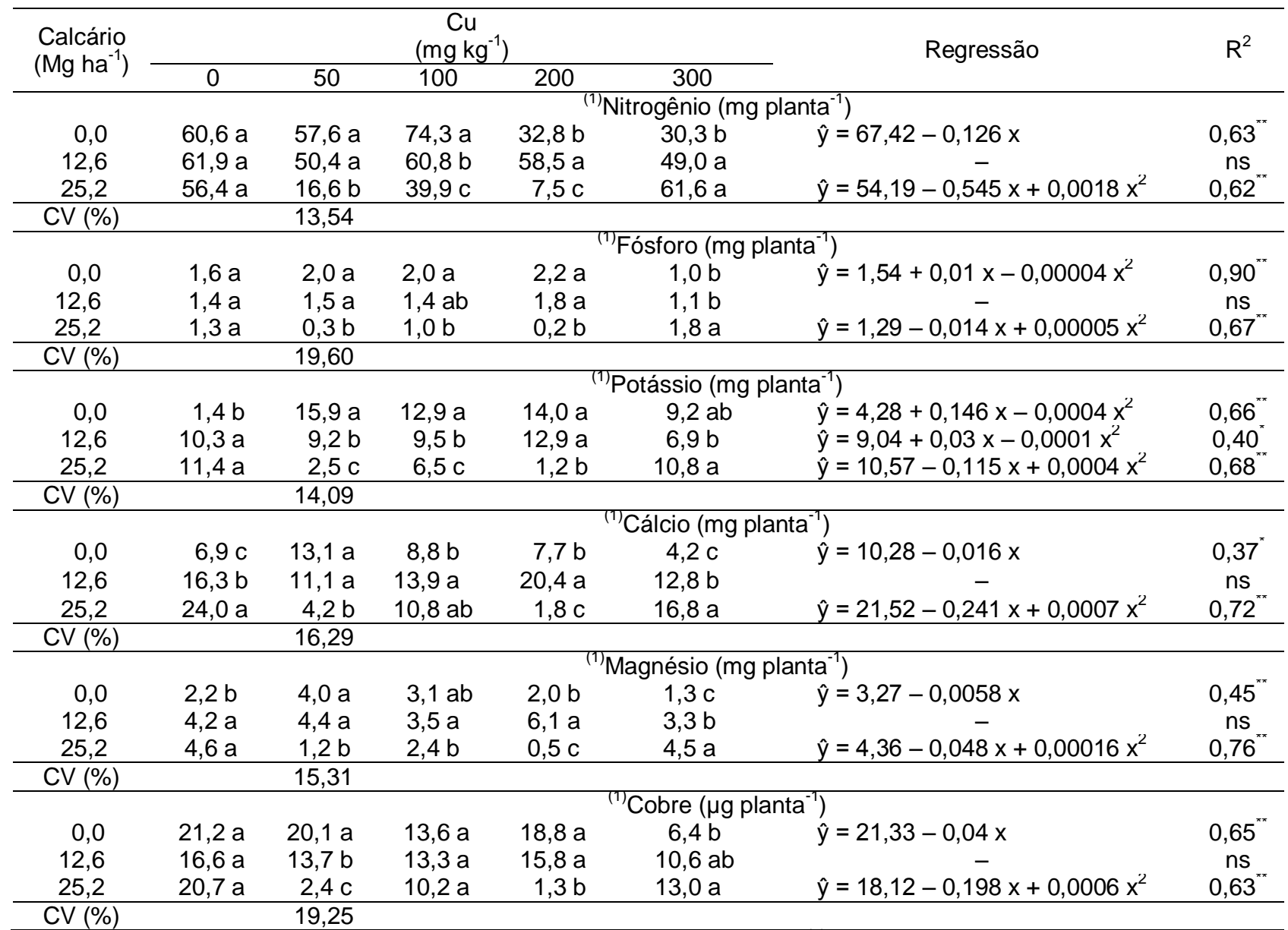

ns - não significativo; ${ }^{*}$ - significativo a $p<0,05 ;{ }^{* *}$ - significativo a $p<0,01 ;{ }^{(1)}$ Valores médios seguidos pela mesma letra na coluna não diferem entre si pelo teste de Tukey $(p<0,05)$. 
Tabela 5 - Valores de N, P, K, Ca, Mg e Cu acumulados na planta inteira de videiras jovens cultivadas em solo com doses crescentes de Cu e de calcário. Values of $\mathrm{N}, \mathrm{P}, \mathrm{K}, \mathrm{Ca}, \mathrm{Mg}$ and $\mathrm{Cu}$ accumulated in whole young vines grown in soil with increasing doses of $\mathrm{Cu}$ and limestone.

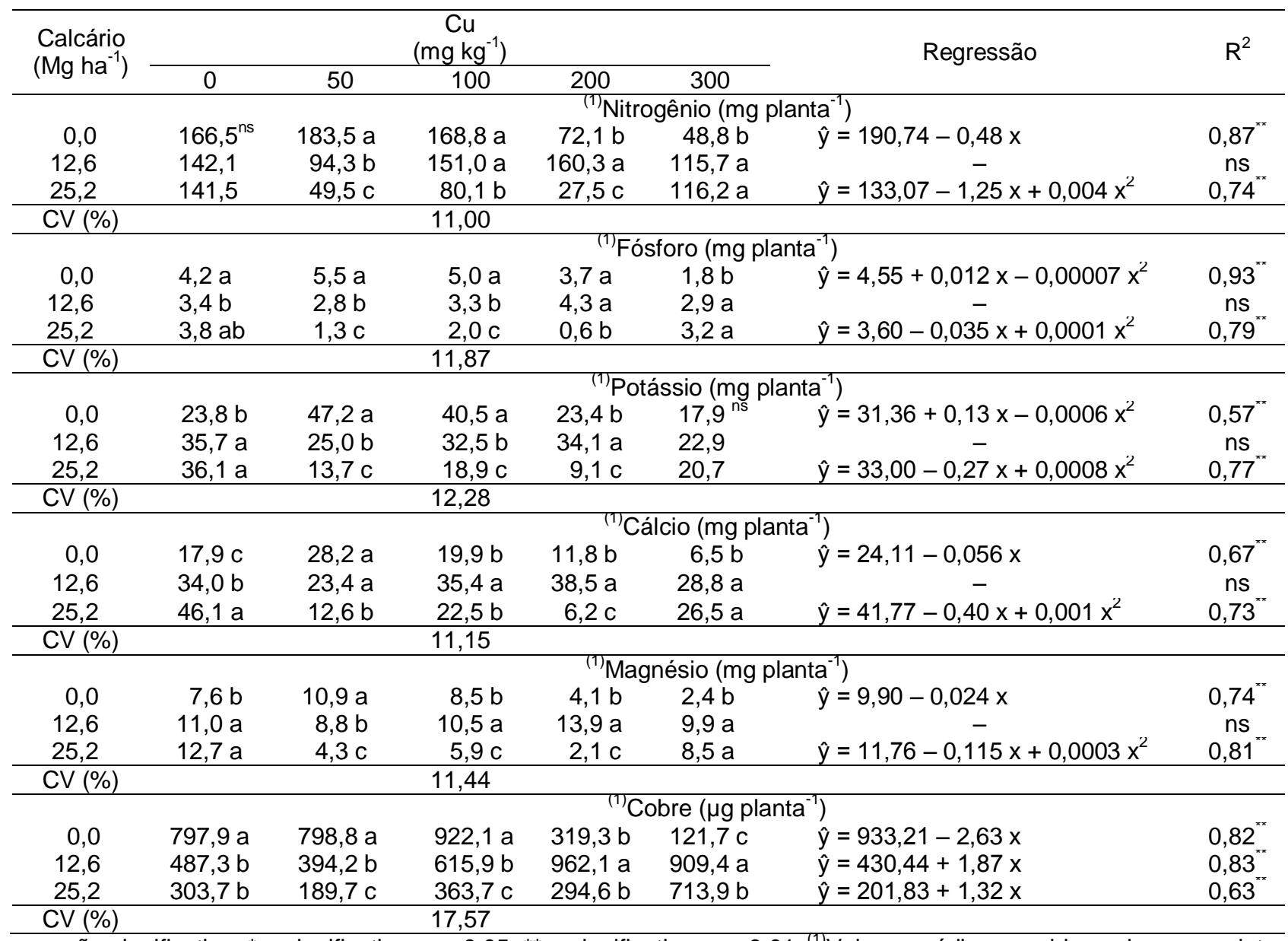

ns - não significativo; ${ }^{*}$ - significativo a $p<0,05 ;{ }^{* *}$ - significativo a $p<0,01 ;^{(1)}$ Valores médios seguidos pela mesma letra na coluna não diferem entre si pelo teste de Tukey $(p<0,05)$.

A adição de calcário no solo reduziu a absorção do $\mathrm{Cu}$ pelas plantas quando foram adicionadas as menores doses de $\mathrm{Cu}$ (Tabelas 3, 4 e 5). Por outro lado, quando foram adicionadas as maiores doses de $\mathrm{Cu}$, a calagem possibilitou maior acúmulo do elemento nas raízes e, por consequência, na planta inteira, em comparação ao solo sem a adição de calcário (Tabelas 3 e 5). No entanto, o incremento no acúmulo de Cu na parte aérea das videiras jovens não foi promovido pela calagem (Tabela 4). Obviamente, esse aumento no acúmulo de $\mathrm{Cu}$ nas raízes pela adição de calcário é decorrente do efeito da calagem no incremento da biomassa de raízes submetidas a altas doses de Cu (Tabela 1), uma vez que a quantidade acumulada é calculada pela multiplicação entre o teor do nutriente (dado não apresentado) e a MS da planta. Mas, além disso, a adição de Ca no solo pela calagem pode ter contribuído para a redução dos efeitos de toxidez nas raízes pelo excesso de $\mathrm{Cu}$, permitindo maior acúmulo do metal pesado neste órgão, mas reduzindo sua distribuição para a parte aérea. Este efeito foi observado por Chen et al. (2013) em estacas de videira cultivadas sob doses crescentes de $\mathrm{Cu}$ e de $\mathrm{Ca}$, e corrobora os resultados do presente trabalho.
$\mathrm{O}$ incremento das doses de $\mathrm{Cu}$ também reduziu o acúmulo de $\mathrm{N}, \mathrm{P}, \mathrm{K}, \mathrm{Ca}$ e $\mathrm{Mg}$ nas raízes, na parte aérea e, consequentemente, na planta inteira de videira jovem, nos tratamentos sem calagem e com a adição de $25,2 \mathrm{Mg} \mathrm{ha}^{-1}$ de calcário (Tabelas 3, 4 e 5). As exceções foram os acúmulos de $\mathrm{P}$ e $\mathrm{K}$ na parte aérea das videiras jovens quando não houve aplicação de calcário, que foram incrementados com o aumento das doses de $\mathrm{Cu}$ até aproximadamente 125 e $183 \mathrm{mg} \mathrm{kg}^{-1}$, nesta ordem, mas decrescendo com doses superiores (Tabela 4). Com a adição de $12,6 \mathrm{Mg} \mathrm{ha}^{-1}$ de calcário, os efeitos do Cu não foram significativos (Tabelas 3, 4 e 5), exceto para o $\mathrm{K}$ na parte aérea, que aumentou com as doses de $\mathrm{Cu}$ aplicadas até $150 \mathrm{mg} \mathrm{kg}^{-1}$, diminuindo a partir daí (Tabela 4).

A diminuição no acúmulo dos macronutrientes nas videiras jovens, provavelmente, é uma consequência da redução na MS das plantas pelo incremento da dose de $\mathrm{Cu}$, o que corrobora os resultados obtidos por Melo et al. (2008). Mas, além disso, a absorção de água e de nutrientes pelas videiras jovens pode ter sido inibida por causa da redução da biomassa das raízes (Kopittke et al., 2009). 
As doses de calcário adicionadas também influenciaram na absorção dos macronutrientes. Quando não foi aplicado $\mathrm{Cu}$ no solo, a calagem favoreceu particularmente o acúmulo de $\mathrm{Ca}$ e $\mathrm{Mg}$ nas videiras jovens. $E$, quando houve incremento da dose de $\mathrm{Cu}$, a aplicação de calcário favoreceu a absorção de $\mathrm{N}, \mathrm{P}, \mathrm{K}, \mathrm{Ca}$ e Mg nas videiras jovens, que havia sido prejudicada nos tratamentos sem calagem (Tabelas 3, 4 e 5). Estes resultados do acúmulo de macronutrientes na planta, somados àqueles das variáveis de crescimento das plantas, indicam que a calagem foi favorável para as videiras jovens, especialmente quando as doses de $\mathrm{Cu}$ foram maiores. Portanto, a aplicação de calcário favoreceu o crescimento das plantas e a absorção de N, P, K, Ca e Mg.

O favorecimento da absorção de macronutrientes pela calagem nos tratamentos onde a dose de Cu foi mais elevada, está relacionado ao incremento da biomassa de raízes pela calagem nesses tratamentos (Tabela 1), o que favorece a absorção de água e de nutrientes pelas plantas. Mas, além disso, o $\mathrm{pH}$ do solo também está fortemente associado à labilidade e à absorção dos macronutrientes pelas plantas (White, 2012). Em pH baixo, como nos tratamentos sem calagem (pH igual a 4,0), os macronutrientes estão predominantemente em formas pouco lábeis, e o incremento do $\mathrm{pH}$ do solo até aproximadamente 6,0 aumenta a disponibilidade desses nutrientes no solo (Sousa et al., 2007). Portanto, a calagem é importante para o estabelecimento de videiras jovens em solo com alto teor de $\mathrm{Cu}$.

\section{Conclusões}

O incremento das doses de cobre reduziu a produção de matéria seca das raízes e da parte aérea, a altura e a área foliar das plantas, as clorofilas $a$ e $b$ (ICF), e a absorção de nutrientes pelas videiras jovens. Porém, a calagem, especialmente com a adição de $12,6 \mathrm{Mg} \mathrm{ha}^{-1}$ de calcário, que elevou o pH até 5,5, diminuiu esses efeitos causados pelo excesso de cobre adicionado.

\section{Referências}

Agbenin JO, Olojo LA (2004) Competitive adsorption of copper and zinc by a Bt horizon of a savanna Alfisol as affected by $\mathrm{pH}$ and selective removal of hydrous oxides and organic matter. Geoderma 119(1):85-95. doi: 10.1016/S0016-7061(03)00242-8.

Borghi M, Tognetti R, Monteforti G, Sebastiani L (2007) Responses of Populus x euramericana $(P$. deltoides $\times$ P . nigra) clone Adda to increasing copper concentrations. Environmental and Experimental Botany 61(1):66-73.

10.1016/j.envexpbot.2007.10.001.

doi:

Brunetto G, Miotto A, Ceretta CA, Schmitt DE, Heinzen J, Moraes MP, Canton L, Tiecher TL, Comin JJ, Girotto E (2014a) Mobility of copper and zinc fractions in fungicide amended vineyard sandy soils. Archives of Agronomy and Soil Science 60(5):609624. doi: 10.1080/03650340.2013.826348.
Brunetto G, Schmitt DE, Comin JJ, Miotto A, Moraes MP, Heinzen J (2014b) Frações de cobre e zinco em solos de vinhedos no Meio Oeste de Santa Catarina. Revista Brasileira de Engenharia Agrícola e Ambiental 18(8):805-810. doi: 10.1590/18071929/agriambi.v18n08p805-810.

Cambrollé J, García JL, Ocete R, Figueroa ME, Cantos M (2013) Growth and photosynthetic responses to copper in wild grapevine. Chemosphere 93(2):294-301. doi: 10.1016/j.chemosphere.2013.04.080.

Chen PY, Lee YI, Chen BC, Juang KW (2013) Effects of calcium on rhizotoxicity and the accumulation and translocation of copper by grapevines. Plant Physiology and Biochemistry 73:375-382. doi: 10.1016/j.plaphy.2013.10.016.

CQFS-RS/SC (2004) Manual de Adubação e Calagem para os Estados do Rio Grande do Sul e de Santa Catarina. 10.ed. SBCS-Núcleo Regional Sul/UFRGS. 400p.

Embrapa (1997) Manual de métodos de análise de solo. Embrapa-CPNS. 212p.

Embrapa (2013) Sistema brasileiro de classificação de solos. 3.ed. Embrapa. 353p.

Ferreira DF (2011) Sisvar: a computer statistical analysis system. Ciência e Agrotecnologia 35(6):1039-1042. doi: 10.1590/S141370542011000600001.

Joris HAW, Fonseca AF, Asami VY, Briedis C, Borszowskei PR, Garbuio FJ (2012) Adsorção de metais pesados após calagem superficial em um Latossolo Vermelho sob sistema de plantio direto. Revista Ciência Agronômica 43(1):1-10. doi: 10.1590/S1806-66902012000100001.

Juang $\mathrm{KW}$, Lee $\mathrm{YI}$, Lai $\mathrm{HY}$, Wang $\mathrm{CH}$, Chen $\mathrm{BC}$ (2012) Copper accumulation, translocation, and toxic effects in grapevine cuttings. Environmental Science and Pollution Research 19(4):1315-1322. doi: 10.1007/s11356-011-0657-3.

Juang KW, Lee YI, Lai HY, Chen BC (2014) Influence of magnesium on copper phytotoxicity to and accumulation and translocation in grapevines. Ecotoxicology and Environmental Safety 104:36-42. doi: 10.1016/j.ecoenv.2014.02.008.

Kopittke PM, Asher CJ, Blamey FPC, Menzies NW (2009) Toxic effects of $\mathrm{Cu}^{2+}$ on growth, nutrition, root morphology, and distribution of $\mathrm{Cu}$ in roots of Sabi grass. Science of the Total Environment 407(16):4616-4621. doi: 10.1016/j.scitotenv.2009.04.041.

Kopittke PM, Kinraide TB, Wang P, Blamey FPC, Reichman SM, Menzies MW (2011) Alleviation of $\mathrm{Cu}$ and $\mathrm{Pb}$ rhizotoxicities in cowpea (Vigna unguiculata) as related to ion activities at root-cell plasma membrane surface. Environmental Science \& Technology 45(11):4966-4973. doi: 10.1021/es1041404. 
Li SX, Wang ZH, Stewart BA (2013) Responses of Crop Plants to Ammonium and Nitrate N. Advances in Agrononomy 118:205-397. doi:10.1016/B978-012-405942-9.00005-0.

Luo XS, Li LZ, Zhou DM (2008) Effect of cations on copper toxicity to wheat root: Implications for the biotic ligand model. Chemosphere 73(3):401-406. doi:10.1016/j.chemosphere.2008.05.031.

Melo GW, Brunetto G, Schafer Junior A, Kaminski J, Furlanetto V. (2008) Matéria seca e acumulação de nutrientes em videiras jovens cultivadas em solos com diferentes níveis de cobre. Revista Brasileira de Agrociência 14(4):72-76.

Michaud AM, Chappellaz C, Hinsinger P (2008) Copper phytotoxicity affects root elongation and iron nutrition in durum wheat (Triticum turgidum durum L.). Plant and Soil 310(1):151-165. doi: 10.1007/s11104-008-9642-0.

Nogueirol RC, Alleoni LRF, Nachtigall GR, Melo GW (2010) Sequential extraction and availability of copper in $\mathrm{Cu}$ fungicide-amended vineyard soils from Southern Brazil. Journal of Hazardous Materials 181(1):931-937.

Panou-Filotheou $\mathrm{H}$, Bosabalidis AM, Karataglis $\mathrm{S}$ (2001) Effects of copper toxicity on leaves of oregano (Origanum vulgare subsp. hirtum). Annals of Botany 88(2):207-214.

Rodighero K, Melo GWB, Freitas RF, Dal Magro R, Scanagatta V, Oliveira PD (2012) A atual recomendação de calcário superestima a necessidade dos solos da Serra Gaúcha. In: Encontro de Iniciação Científica, 10, Encontro de Pós-Graduandos da Embrapa, 6., 2012, Bento Gonçalves. p.35.

Ruyters S, Salaets P, Oorts K, Smolders E (2013) Copper toxicity in soils under established vineyards in Europe: A survey. Science of the Total Environment 443:470-477. doi: 10.1016/j.scitotenv.2012.11.001.
Sheldon AR, Menzies NW (2005) The effect of copper toxicity on the growth and root morphology of Rhodes grass (Chloris gayana Knuth.) in resin buffered solution culture. Plant and Soil 278(1):341-349. doi: 10.1007/s11104-005-8815-3.

Sousa DMG, Miranda LN, Oliveira AS (2007) Acidez do solo e a sua correção. In: Novais RF, Alvarez VHV, Barros NF, Fontes RLF, Cantarutti RB, Neves JCL (ed) Fertilidade do solo, Sociedade Brasileira de Ciência do Solo. p.205-274.

Tedesco MJ, Gianello C, Bissani CA, Bohen H, Volkweiss SJ (1995) Análises de solo, plantas e outros materiais. 2 ed. UFRGS. $174 p$.

Toselli M, Baldi E, Marcolini G, Malaguti D, Quartieri M, Sorrenti G, Marangoni B (2009) Response of potted grapevines to increasing soil copper concentration. Australian Journal of Grape and Wine Research 15(1):85-92. doi: 10.1111/j.17550238.2008.00040.x

White PJ (2012) lon uptake mechanisms of individual cells and roots: Short-distance transport. In: Marschner $P$ (ed) Marschner's mineral nutrition of higher plants (third edition), Academic Press. p.6-47. doi:10.1016/B978-0-12-384905-2.00002-9

Yruela I (2009) Copper in plants: acquisition, transport and interactions. Functional Plant Biology 36(5):409-430. doi: 10.1071/FP08288

Zengin FK, Munzuroglu O (2005) Effects of some heavy metals on content of chlorophyll, proline and some antioxidant chemicals in bean (Phaseolus vulgaris L.) seedlings. Acta Biologica Cracoviensia. Series Botanica 47(2):157-164. 